\title{
Clear Cell Variant of Calcifying Epithelial Odontogenic Tumor without Calcification: A Rarity
}

\author{
${ }^{1}$ Vimi Sunil Mutalik, ${ }^{2}$ Prasanna Nichat, ${ }^{3}$ Sunitha Carnelio, ${ }^{4}$ Monica Solomon, ${ }^{5}$ Raghu Radhakrishnan
}

\begin{abstract}
Calcifying epithelial odontogenic tumor (CEOT) is a rare, benign, locally aggressive odontogenic epithelial tumor that affects the jaws. Although there are numerous reports on the variants of CEOT, occurrence of clear cells with complete absence of calcification has been a rarity. Histochemical analysis of tumor cells revealed glycogen granules with PAS staining, with absence of CD 1a staining in clear cells, while the amyloid-like deposit associated with clear cells showed green birefringence with Congo red. We report an unusual variant of CEOT occurring in a 27 years old male patient.
\end{abstract}

Keywords: Clear cell, Odontogenic tumor, PAS, Congo red.

How to cite this article: Mutalik VS, Nichat P, Carnelio S, Solomon M, Radhakrishnan R. Clear Cell Variant of Calcifying Epithelial Odontogenic Tumor without Calcification: A Rarity. J Contemp Dent Pract 2014;15(1):119-121.

Source of support: Nil

Conflict of interest: None declared

\section{INTRODUCTION}

Background: Clear Cell Odontogenic Tumor (CEOT) is a rare form of odontogenic tumor, which was first described in 1955 as a separate entity by Pindborg and hence the eponym Pindborg tumor. It usually affects middle aged individuals, with mandible being the most common site of occurrence. The most distinctive feature of classical CEOT is the presence of amyloid globules and liesegang ring calcifications in the tumor tissue. ${ }^{1}$ Although the occurrence of clear cells in CEOT is a rarity it has been reported in approximately $8 \%$ of cases of CEOT., ${ }^{2,3}$ The absent or minimal calcification in CEOT however is exceptional as we present one such case of noncalcifying clear cell variant of CEOT. The significance of clear cells in CEOT with regard to its clinical behavior and prognosis is discussed.

\footnotetext{
1,2 Lecturer, ${ }^{3,4}$ Professor, ${ }^{5}$ Professor and Head

${ }^{1}$ Department of Oral Diagnostic Sciences, International Medical University, Kuala Lumpur, Malaysia

${ }^{2}$ Department of Oral and Maxillofacial Pathology, Mahatma Gandhi Vidya Mandir KBH Dental College, Nasik, India

3-5Department of Oral and Maxillofacial Pathology, Manipal College of Dental Sciences, India
}

Corresponding Author: Raghu Radhakrishnan, Professor and Head, Department of Oral and Maxillofacial, Pathology, Manipal College of Dental Sciences, India, e-mail: aparagh@yahoo.com

\section{CASE REPORT}

A 27-year-old male was referred to the out patient unit of the University Dental School with a chief complaint of swelling in the lower left poster region. Clinical examination did not divulge any obvious abnormality as stated by the patient and the medical history was noncontributory. The past dental history suggested that the patient underwent an uneventful extraction in the same region about 4 months back, following which the patient was rather uneasy with slight discomfort. Orthopantomogram revealed a well defined radiolucent area with a smoothly corticated periphery in the body of the mandible extending from the distal aspect of 34 to mesial aspect of 37 . Incisional biopsy was performed and microscopic examination revealed nests and sheets of polygonal cells with clear cytoplasm with centrally placed nuclei (Fig. 1) interspersed with amyloid like material giving the impression of clear cell variant of CEOT. Histochemical examination of clear cells with periodic acid Schiff (PAS) reaction demonstrated the presence of glycogen (Fig. 2), while the confirmation of amyloid like material was confirmed with Congo red reaction (Fig. 3). However, anti CD 1a immunostaining for clear cells was found to be negative (Fig. 4).

\section{DISCUSSION}

Clear cell variant of CEOT is a rare subset, which has been reported in approximately $8 \%$ of CEOT. ${ }^{2}$ It has been described as a slow growing lesion, which causes

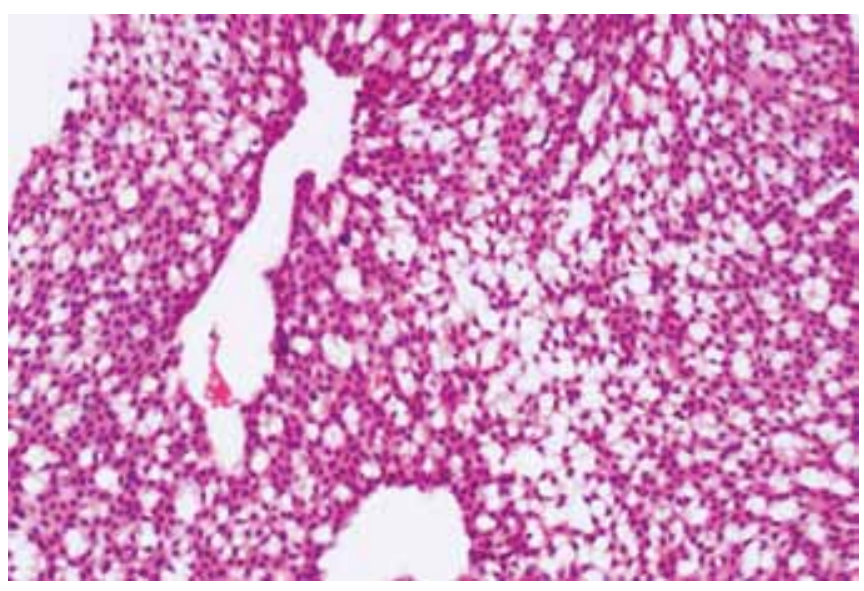

Fig. 1: Clear cells showing vacuolated foamy cytoplasm (H \& E Stain-Original Magnification 10x) 
significant expansion of jaw bones resulting in resorption and displacement of involved teeth. ${ }^{3}$ The occurrences of minimal or absent calcifications in CEOT is rather unusual as only three cases of this type have been reported. The concomitant presence of Langerhans cells in these subtypes of CEOT offers many a view regarding its pathogenesis. ${ }^{4}$

Characteristically the tumor shows islands, strands or sheets of polygonal epithelial cells with centrally placed

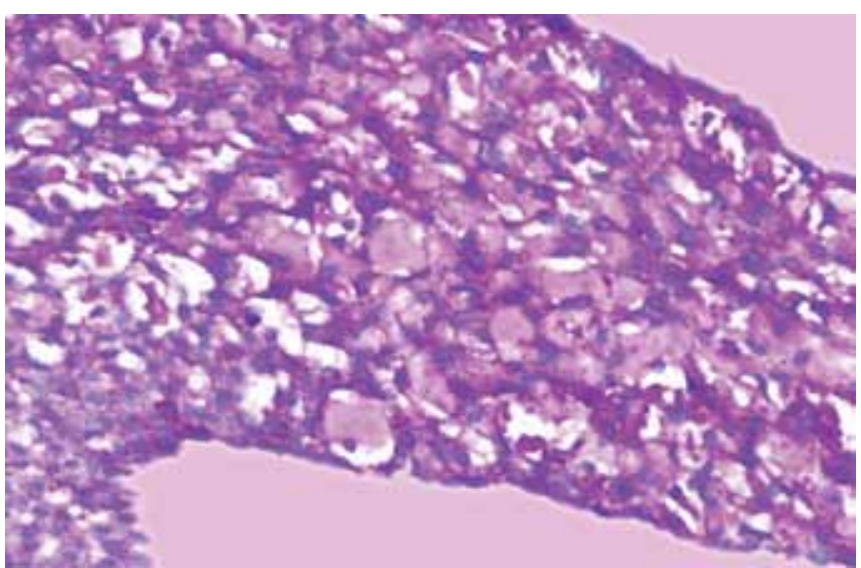

Fig. 2: PAS positivity seen in the clear cells (Per lodic Acid Schiff-Original Magnification 20x)

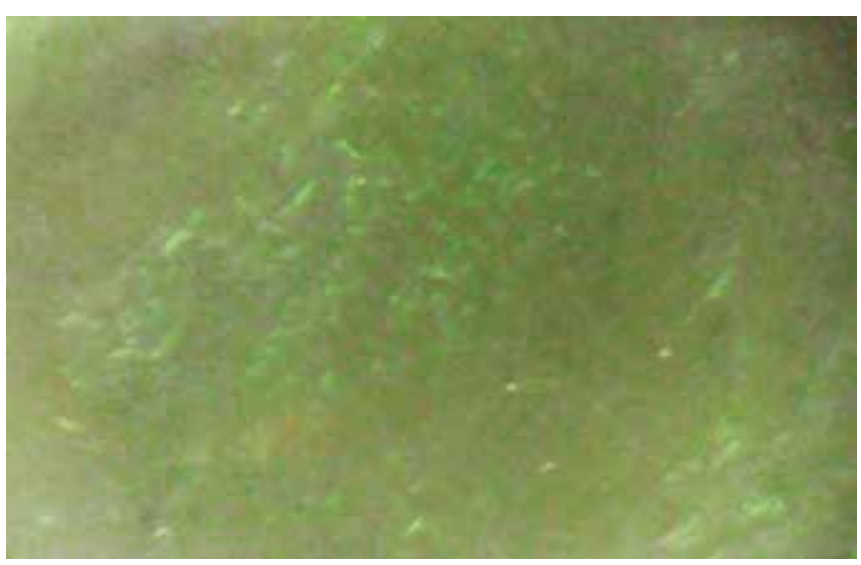

Fig. 3: Amyloid showing apple green birefringence (Congo Red Stain-Original Magnification 40x)

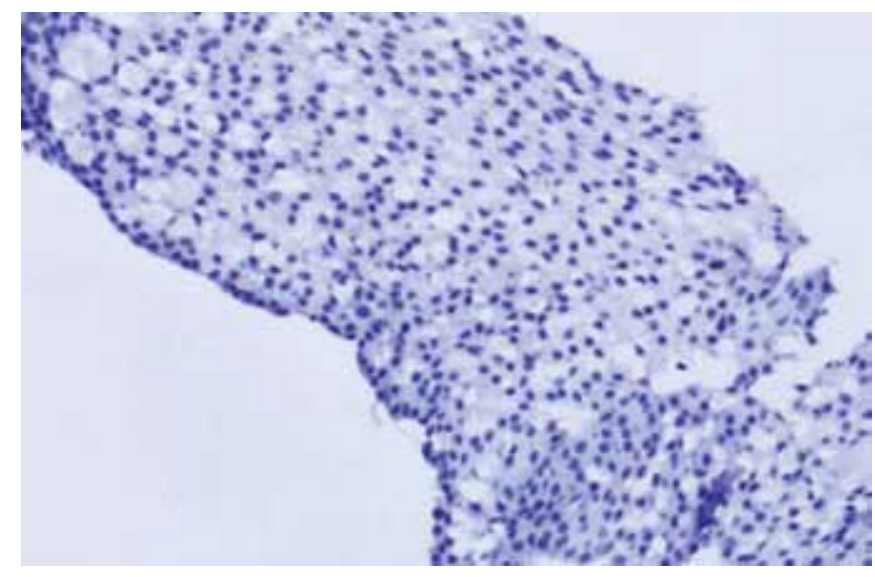

Fig. 4: Nonreactive immunostaining with anti CD 1a (Immunohistochemistry-Original Magnification 10x) hyperchromatic nuclei and amorphous eosinophilic globules of amyloid like material in the fibrous connective tissue. Concentric liesegang ring like calcifications are often noted within these amyloid globules. ${ }^{5}$ Unlike with previous reports, where the lesion presented between the fourth to fifth decade of life in the maxillary canine-premolar region, our case was noted in a young patient in the lower mandibular region. ${ }^{4}$ Incidentally, two of the previous cases reported in literature were also noted following extraction of teeth in the involved area similar to our case. ${ }^{1,5}$ However, histologically the islands or nests of tumor epithelial cells was devoid of calcification in contrast to the stereotypic CEOT. Also, features like cellular and nuclear pleomorphism which is so characteristic of conventional CEOT was not evident.

A special feature was the presence of clear cells amidst the tumor cells, which were PAS positive. Clear cells were thought to be degenerated or cyto differentiated epithelial cells. ${ }^{6}$ However, Asano et al ${ }^{1}$ reported a case of CEOT with Langerhans cells, and the cells failed to exhibit PAS positivity. Since anti CD 1a immunostaining was negative in our case the diagnosis was confirmed as a noncalcifying clear cell variant of CEOT. Importantly, CEOT with clear cells have to be dealt with suspicion as they are considered to be more aggressive compared to the conventional CEOT. ${ }^{3}$

Clinical behavior of similar cases that have been reported previously have shown good prognosis without recurrence. This was attributable to the presence of Langerhans cells, which was perceived to result in the regression of these lesions by immune regulation. ${ }^{1}$ Solomon et al put forth a contrarian view stating that calcifications and amorphous substance indicate greater tumor differentiation, which accounts for lower recurrence of the tumor. Convincingly though, the tumors which were less productive were also less differentiated and therefore posed a risk of being more aggressive. ${ }^{7}$ Furthermore, clear cell variant is considered to be a variant of low grade odontogenic carcinoma with higher recurrence rate of $10.52 \%{ }^{8}$

\section{CONCLUSION AND CLINICAL SIGNIFICANCE}

Since all the three reported cases have originated from the Japanese literature, ${ }^{1,4,5}$ the effect of ethinic background has to be taken into consideration. Our cases responded well to surgical treatment without any indication of recurrence. However, the clinical behavior of CEOT which shows a combination of clear cells and absence of calcifications deserves regular follow-up. This is case is highlighited here owing to its rarity and emphasis to follow-up of these subsets of CEOT may provide greater clarity about its clinical behavior. 


\section{REFERENCES}

1. Asano M, Takahashi T, Kusama K, Iwase T, Hori M, Yamanoi H, Tanaka H, Moro I. A variant of calcifying epithelial odontogenic tumor with langerhans cells. J Oral Pathol Med 1990;19(9):430-434.

2. Habibi A, Saghravanian N, Zare R, Jafarzadeh H. Clear cell variant of extraosseous calcifying epithelial odontogenic tumor: a case report. J Oral Sci 2009;51(3):485-488.

3. Anavi Y, Kaplan I, Citir M, Calderon S, Tikva P, Aviv T. Clearcell variant of calcifying epithelial odontogenic tumor: clinical and radiographic characteristics. Oral Surg Oral Med Oral Pathol Oral Radiol Endod 2003;95(3):332-339.

4. Wang YP, Lee JJ, Wang JT, Liu BY, Yu CH, Kuo RC, Chiang CP. Noncalcifying variant of calcifying epithelial odontogenic tumor with Langerhans cells. J Oral Pathol Med 2007;36(7):436-439.
5. Takata T, Ogawa I, Miyauchi M, Ijuhin N, Nikai H, Fujita M. Noncalcifying Pindborg tumor with Langerhans cells. J Oral Pathol Med 1993;22(8):378-383.

6. Schmidt-Westhausen A, Philipsen HP, Reichart PA. Clear cell calcifying epithelial odontogenic tumor. A case report. Int J Oral Maxillofac Surg 1992;21(1):47-49.

7. Solomon MP, Vuletin JC, Pertschuk LP. Calcifying epithelial odontogenic tumor: a histologic, histochemical, fluorescent and ultrastructural study. Oral Surgery Oral Medicine Oral Pathology 1975;40(4):522-530.

8. Rangel AL, da Silva AA, Ito FA, Lopes MA, Almeida OPD, Vargas PA. Clear cell variant of calcifying epithelial odontogenic tumor: is it locally aggressive? J Oral Maxillofac Surg 2009; 67(1):207-211. 